\title{
Building Performance and Academic Performance of University Campuses:
}

\author{
Post Occupation Evaluation of Projects With Foreign Loan Financing
}

\author{
M. Syaom Barliana, Budi Kudwadi*, Dedy Suryadi, Fauzi Rahmanullah \\ Department of Architectural Engineering Education \\ Universitas Pendidikan Indonesia \\ Bandung, Indonesia \\ *bkudwadi@upi.edu
}

\begin{abstract}
Amidst the limited state budget, one of the efforts to improve the quality of higher education facilities and infrastructure is obtaining through foreign loan and grant financing (PPHLN). The problem, does physical transformation has a balanced impact on improving the quality of higher education, namely, education, research, and community service? Research with the Post Occupational Evaluation method will focus on architectural transformation related to building performance, as well as its implications for the academic performance of lecturers and the performance of higher education institutions. The study will also compare the performance of buildings and the academic performance of universities that obtain and do not or have not yet received PHPLN. The results of the study will shows there is no significant different between building performance and academic performance which get PPHLN or not. However, individually, there is difference between building performance and academic performance UPI (PPHLN) with UNP (PPHLN) and UNIMED also UNM (Non-PPHLN).
\end{abstract}

Keywords-foreign loan financing, building performance, academic performance, post-occupation evaluation

\section{INTRODUCTION}

Educational infrastructure is one of the instrumental inputs in education and learning. As an instrumental input, educational facilities are one of the determining factors in efforts to guarantee the quality of education. The assumption is that if other determinants of quality, such as curriculum, teacher competence, and the capacity of students are very supportive, the higher the level of building performance, the higher the quality of education and learning.

The availability of educational infrastructure does not only concern quality, but also education participation and equity. The gross education enrollment rate (GER) for tertiary education in Indonesia is around $34 \%$ in 2019. This GER is still far below that of neighboring countries such as Singapore and Malaysia which have reached above $90 \%$. One of the problems, of course, is the vast area of Indonesia, with a fairly high level of differentiation and disparity in progress between regions. Therefore, in addition to quality and quantity, educational equality is also a crucial issue.

One of the causes of the disparity in education is the limited education infrastructure, including higher education. In fact, laboratory buildings and equipment are expensive long-term resources, and must be designed to reflect the vision and strategy of educational institutions [1]. In the case of Indonesia, this vision and strategy concerns increasing the quantity, quality and relevance of education. This is an extraordinary challenge for the university, in terms of obtaining and managing funding for building educational facilities.

The quality of educational facilities that accommodate various activities of the learning process can be measured, among others, through the design functionality and building performance. Functionality is a property given to infrastructure artifacts, in order to create a spatial usability effect [2]. This means that the quality and variety of facilities will reflect the demands and needs of users for good productivity. This has to do with how well the building directly supports the activities in it. How effective is a building and the environment to facilitate activities and increase user comfort [3]. Also, how responsive is the building to the specific needs of the organization and its inhabitants, both qualitatively and quantitatively.

The condition of the physical quality and functional effectiveness of the building is very important in supporting the effectiveness of education. The effectiveness of this building must be maximized, not only in terms of using construction and operational costs of the building, but also in terms of user satisfaction. A successful educational building is indicated by the extent to which the building functions, how students and teachers make use of these spaces, and how the design promotes the educational process [4]. Therefore, a building's ability to successfully achieve its goals is a measure of its success. 
Building performance, is the output of the quality of facilities that determines the quality of education and learning. According to Son and Yuen, there are four main indicators for measuring building performance, namely: legality requirements and regulatory compliance, functional requirements related to building functions, user requirements related to comfort and costs to be incurred by users, and performance requirements. related to the physical performance of buildings and installation of complementary infrastructure [5].

In reality, in the context of higher education in Indonesia, there is still a wide gap between the ideals of the need for quality educational facilities and the reality that can be provided, both at public and private universities. From the approximately 4500 public and private universities, it seems that no more than $20 \%$ meet the quality standards of facilities and infrastructure.

In the midst of limited state budgets, one of the efforts to improve the quality of facilities and infrastructure for higher education is obtained through financing foreign loans and grants (PPHLN). Compared to domestic sources of financing, which generally build each building in stages, PPHLN builds and develops a lot of university campuses at once and is comprehensive. Many college campuses that obtain PPHLN, are transforming rapidly into representative campuses and have adequate educational facilities.

The problem is, does this architectural transformation have a balanced impact on improving the quality of the tridharma of higher education, namely education, research, and community service? Research using the POE method will focus on architectural transformation, which is related to building performance, and its implications for higher education academic performance. POE has a significant role in improving the products and processes of the construction industry, as well as ensuring the fit between physical, environmental and social requirements and long-term goals $[6,7]$.

Based on the background of the problem, this study has three objectives. First, to describe the level of performance of the college campus buildings after PPHLN construction. Second, describe the level of individual lecturer academic performance. Third, examining the relationship between building performance and academic performance of lecturers and the difference in the level of the relationship between postconstruction PPHLN and Non-PPHLN colleges.

So far, there has been no research in Indonesia that has evaluated the implementation of construction and performance of higher education institutions that are funded by PPHLN. This research is important to do, to observe the extent to which large investments originating from debt, which are ultimately passed on to the people through taxes, have implications for balanced economic and social returns. Thus, a description of the effectiveness of development financing will be obtained in improving the quality of higher education.

Building performance can be measured from 4 (four) requirements, namely: functional requirements related to building functions, performance requirements related to the physical performance of buildings and installation of complementary infrastructure, legality requirements and regulatory compliance, as well as user requirements related to comfort and costs. that the user must issue [5].

Functional requirements, means that the building must be able to accommodate user activities properly. In the words of Okolie and Ogunoh, functionality is a property provided to create a practical effect on the use of space, which meets the demands and needs of users to get good productivity [1]. The functional element, therefore, deals with the fit between the building and its activities. That is, how well the building directly supports the activities in it, responsive to the specific needs of the organization and its residents, both qualitatively and quantitatively.

Building performance is a philosophy and at the same time a science based on the premise that buildings must meet the requirements of safety, health, comfort, efficiency, and have sufficient durability [8]. In line with the view above, Rush and Smith tried to see building performance as a whole, an integration of factors; spatial performance, thermal performance, ventilation conditions, acoustics and visual performance, as well as the total integrity of the building $[9,10]$.

\section{RESEARCH METHODOLOGY}

This study uses a quantitative approach, with a combination of two methods: Post Occupation Evaluation (POE) for building performance variables, as well as comparative descriptive research methods to compare building performance levels and academic performance, and correlational descriptive to see the relationship between building performance and building performance. academic performance.

With regard to $\mathrm{POE}$, there are three categories of $\mathrm{POE}$, the implementation of which depends on the type and size of the building, the client's objectives, and the expected depth of evaluation. Preiser et al., mention POE indicative, investigative, and diagnostic, each of which consists of three phases: planning, organizing and implementing [11].

This research is at level 2 and 3, namely the Investigative and Diagnostic POE category, with the aim of evaluating the extent to which the performance of the college campus buildings built by PPHLN funds, which is then seen in relation to academic performance. However, because this research was conducted during the Covid-19 pandemic, data collection techniques such as field observations and physical measurements of buildings and the environment were not possible. Therefore, this study uses two data collection techniques, namely, the online questionnaire technique and documentation study.

The location of the research was conducted on a college campus built with PPHLN funds, especially the Islamic Development Bank (IsDB) as a lender. The tertiary institution that was selected purposively as the unit of analysis was the ex- 
IKIP University or LPTK (Educational Personnel Education Institute), with three categories for comparability. First, a university that has been built and used for about 10 years, namely the Indonesian Education University (UPI). Second, universities that are post-construction and have been in use for at least two years, namely Padang State University (UNP). Third, universities that have not obtained PPHLN, namely Makassar State University (UNM) and Medan State University (UNIMED).

The research subjects chosen as respondents were faculty leaders, study program heads, and lecturers at the Faculty of Engineering (FPTK at UPI), which resulted in prospective teaching staff (productive teachers) in SMK. Data obtained from respondents on variable $X$ (Building Performance) and variable Y (Academic Performance), by distributing a closed questionnaire to 160 respondents. Only 102 respondents returned the questionnaire. Scoring on the questionnaire instrument items used a rating scale (1-5). The magnitude of the results is obtained by comparing the achievement score (SR) with the maximum score (SM), namely SR / SM x 100 and the results are compared with the Building Performance Criteria table as shown in the table 1 below:

TABLE I B BULDING PeRFormance CRITERIA

\begin{tabular}{|l|l|}
\hline \multicolumn{1}{|c|}{ Score Range } & \multicolumn{1}{c|}{ Category } \\
\hline $0-20$ & Very bad \\
\hline $21-40$ & Bad \\
\hline $41-60$ & Pretty good \\
\hline $61-80$ & Good \\
\hline $81-100$ & Very good \\
\hline
\end{tabular}

Likewise for variable $\mathrm{Y}$, the results are compared with the Lecturer Academic Performance Criteria table as shown in the table 2 below:

TABLE II. LECTURER ACADEMIC PERFORMANCE CRITERIA

\begin{tabular}{|l|l|}
\hline \multicolumn{1}{|c|}{ Score Range } & \multicolumn{1}{c|}{ Category } \\
\hline $0-20$ & Very low \\
\hline $21-40$ & Low \\
\hline $41-60$ & Pretty high \\
\hline $61-80$ & High \\
\hline $81-100$ & Very high \\
\hline
\end{tabular}

To see whether the academic performance of lecturers from the four tertiary institutions was the same or significantly different, a difference test was calculated using the homogeneity test and Anova analysis.

Testing using the correlation technique is carried out to determine whether there is a relationship (correlation) between variables, namely variable $\mathrm{X}$ (Building Performance) to variable Y (Lecturer Academic Performance). Based on the results of data distribution, analysis of the correlation test was carried out in this study using the Pearson product moment correlation formula.

With regard to the calculation analysis to obtain the effect value, because the statistical requirements are not met, the calculation is carried out using the contribution calculation. The results of the calculation of the amount of contribution are done by calculating the coefficient of determination (KD) in variable $\mathrm{X}$ against variable $\mathrm{Y}$ using the formula $\mathrm{KD}=\mathrm{r} 2 \mathrm{x}$ $100 \%$.

\section{RESULTS AND DISCUSSION}

The results showed that the building performance conditions of all PTNs which were the object of the study were grouped into the Good category.

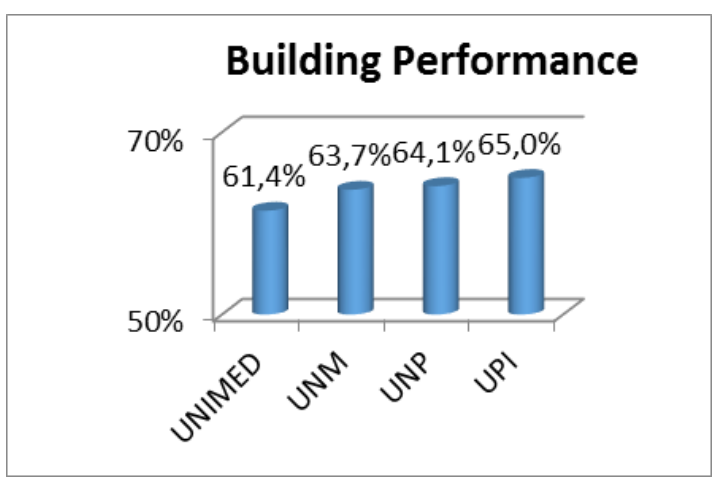

Fig. 1. Building performance diagram.

The data shows, that: The performance level of the UNIMED college campus buildings shows that the average performance reaches $61.4 \%$, UNM reaches $63.7 \%$, UNP reaches $64.1 \%$, and UPI is performing $65.0 \%$ of its maximum performance capacity. All of them are in the Good category.

Based on the ANOVA output above, it is known that the Sig value is $0.474>0.05$, so it is concluded that the average performance of the four campus buildings is significantly equal.

In contrast, in academic performance, there are significant differences between universities. The results showed that the academic performance conditions of the lecturers of UNIMED, UNM, and UNP were in the Low category, while UPI was quite high.

\section{The Level of Academic Performance of Lecturer}

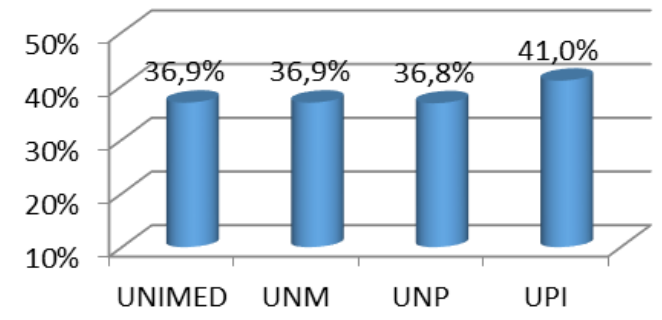

Fig. 2. The level of academic performance of lecturer. 
Thus it can be concluded that the academic performance of lecturers for each PTN LPTK is as follows: The level of academic performance of Lecturers (individuals) at UNIMED colleges shows that the average performance reaches $36.9 \%$, UNM $36.9 \%$, UNP reaches $36,8 \%$. All three are in the Low category; The level of academic performance of UPI lecturers reached $41.0 \%$, including in the High Enough category.

Based on the ANOVA output above, it is known that the Sig value is $0.007<0.05$, so it can be concluded that the average of the four lecturers' academic performance is significantly different.

Furthermore, looking at the contribution of building performance variables to the academic performance of lecturers, it is obtained from the calculation of the coefficient of determination, the results of which can be seen in Figure 3. below.

\section{The Contribution of Building Performance to the Lecturer Academic Performance}

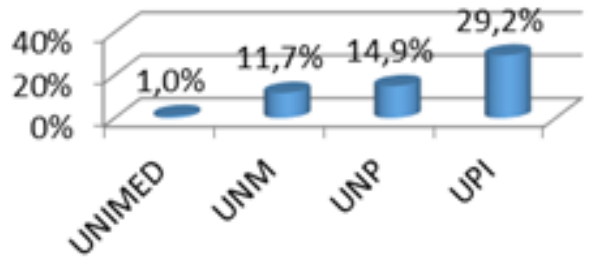

Fig. 3. The contribution of building performance to the lecturer academic performance.

Based on the diagram above, the position of the four universities can be described as follows: The correlation between building performance and academic performance of lecturers at UNIMED shows a positive direction with a correlation coefficient of $r=0.1$ (very low) and the contribution of building performance to lecturers' academic performance is only $1 \%$, so it can be concluded that it doesn't contribute; The correlation between building performance and academic performance of lecturers at UNM shows a positive direction with a correlation coefficient of $r=0.34$ (low) and the contribution of building performance to the academic performance of lecturers is only $11.7 \%$; The correlation between building performance and academic performance of UNP lecturers shows a positive direction with a correlation coefficient of $r=0.39$ (low) and the contribution of building performance to academic performance reaches only $14.9 \%$; The correlation between building performance and academic performance of lecturers at UPI shows a positive direction with a correlation coefficient of $\mathrm{r}=0.54$ (moderate) and the contribution of building performance to academic performance reaches only $29.2 \%$.
Referring to the results of this study, there are several interesting facts that deserve to be discussed. First, there is no significant difference in the performance of university buildings, whether built with PPHLN or non-PPHLN. The problem is that there is a limitation of research during the COVID-19 pandemic, which uses subjective measurements based on user perceptions, not objective measurements directly into the field. Thus, there is a possibility of differences in the level of expectations and assessments of lecturers on the quality of building performance. This difference occurs because of differences in experience, taste, and includes geographical factors, Java and Outside Java.

Collectively, there is no significant differences between building performance and academic performance as well as the relationship between those two, whether the campus build by PPHLN funding or Non-PPHLN. However, if its measured individually, there is different relationship between building performance and academic performance of UPI with UNP, UNIMED, and UNM. The reason is due to UPI campus already build for a significant amount of time (more than 10 years), Thus, it already give the influence towards academic culture development, which implicated towards the enhancement of academic performance. Meanwhile, UNP was build by PPHLN fund recently (less than three years), thus, the impact still barely seen.

\section{CONCLUSION}

Subjective measurement according to users perception towards building performance, shows the result as follow: (a) building performance UPI and UNP (PPHLN) collectively and individually on the level of good; (b) building performance UNIMED and UNM (Non PPHLN) collectively and individually on the level of good.

Subjective measurement based on lecturer perception and the head of faculty/program study towards academic performance, shows the result as follow: academic performance of UPI and UNP lecturer (PPHLN) is in fair level, individually, UPI in good level while UNP in fair level; (b) academic performance of lecturer UNIMED and UNM collectively and individually is in the fair level

The results of the correlation hypothesis test show the following results: (a) UPI and UNP Building Performance (PPHLN) has a low correlation with Academic Performance. On its own, UPI Building Performance has a moderate correlation with Academic Performance, while UNP has low correlation; (b) The performance of UNIMED and UNM (NonPPHLN) buildings individually or collectively has a low correlation with academic performance.

Collective test shows there is no significant different between building performance and academic performance which get PPHLN or not. However, individually, there is difference between building performance and academic performance UPI (PPHLN) with UNP (PPHLN) and UNIMED also UNM (Non-PPHLN). 


\section{ACKNOWLEDGMENT}

Thank you to the leaders of the Faculty of Engineering, Technology and Vocational Education, heads of departments, heads of study programs, and lecturers of UNIMED, UNM, UNP, and UPI who have been willing to become respondents. We also thank the Manager of Project Management Unit and Project Implementation Unit of AKSI-ADB for UPI as Center of Excellence of Technical and Vocational Education for Teachers, who funded this research.

\section{REFERENCES}

[1] K.C. Okolie and P.E. Ogunoh, "Assessment of functional and environmental indicators in the performance of buildings in Federal Universities of South East Nigeria," Int. J. Eng. Adv. Technol. Stud., vol. 1, no. 2, pp. 1-11, 2013

[2] A. Warell, Design Synthetics: A Functional Approach to Visual Product Form. Chalmers University of Technology. Gothenburg. Theory, Model and Methods. In: Alexander, K. (Eds). Usability of Workplaces. CIB Report, Publications 306. P. 84, 2001.

[3] M.S. Barliana, Desain Sekolah Ramah Anak. Seminar Nasional. Bandung: KMA Kridaya, Arsitektur UPI, 2015.
[4] T. Heitor, International Design Principles for Schools: Potential Problems and Challenges. OECD Programme on Educational Buildings. [Online]. Available from www.oecd.org/dataoecd/61/45/35469220df., 2005.

[5] L.H. Son and G.C.S. Yuen, Building Maintenance Technology. Basingstoke. United Kingdom: Palgrave MacMillan, 1993.

[6] H. Hartman and L. Mark, Look and learn. Architects' Journal. Retrieved from http://www.architect sjournal.co.uk/footprint/look-andlearn/8643490.article, 2013

[7] J. Watson, C.W. Clegg, R. Cowell and N. McCarthy, Built for living: Understanding behaviour and the built environment through engineering and design. Retrieved from http://www.raeng.org.uk/publications/reports/builtfor-livingunderstanding-behaviour, 2015.

[8] Dunning, Skye., Morrow, Danny, What is Home Performance? Avaliable at http://www.bpsgreenhomes. com/learn/what-is-homeperformance, 2019.

[9] R.D. Rush, (Ed), The Building Systems Integration Handbook. New York: The American Institute of Architects, John Wiley \& Sons, 1986.

[10] P.R. Smith and W.G. Julian, Building Science. London: Applied Science Publishers Limited, 1976.

[11] Preiser, Wolfgang, Hardy, Andrea E., Schramm, Ulrich (Eds.), Building Performance Evaluation: From Delivery Process to Life Cycle Phases. Springer International Publishing, 2018. 